\title{
Energetic, Techno-Economic and Environmental Analysis of a Biorefinery from Sugarcane Bagasse at Different Scales
}

\author{
Daissy Lorena Restrepo S., Ashley Sthefanía Caballero G., Christian David Botero G., \\ Carlos Ariel Cardona A.*

\begin{abstract}
Universidad Nacional de Colombia sede Manizales, Instituto de Biotecnología y Agroindustria. Laboratorio de
\end{abstract} \\ Equilibrios Químicos y Cinética Enzimática. Departamento de Ingeniería Química. Manizales, Colombia
}

\begin{abstract}
Sugarcane bagasse is a waste generated in around the world in different quantities. It residue can be used to obtain different products under the concept of the biorefinery. Where the energetic technical, economic and environmental viability can be influenced by the scale of processing. In this sense, an analysis of the size of the biorefinery (scale analysis) was performed to determine the point of economic viability. In addition, an energy analysis was carried out, which allowed to identify the influence that has the processing scale on the energy changes presented throughout the process. As a result, it was possible to observe the importance of the analysis of the scale of a process for the determination of the point in which it is obtained not only an energetic but also economic viability.
\end{abstract}

Keywords: Sugarcane bagasse, biorefinery, scale analysis, energetic analysis

\section{Introduction}

Biorefineries are designed to maximum approach a raw material [1]. This is achieved by obtaining a wide range of added-value products as biofuels, biochemical, biomaterials and others [2] Among the raw materials more attractive to use in a biorefinery are the residues generated in other industrial processes. The use of these waste helps to mitigate the environmental impact generated by them [3]. However, when is considering the design of a biorefinery should be enumerated other aspects such as energy, economic and social, with that the design of a biorefinery is based on the correct interaction of these aspects. In this way, a wide spectrum of possibilities is generated by the design of biorefineries which must be debated in the step of conceptual design.

Some authors have mentioned the importance of taking into account the mass and energy integration of the processes in the conceptual design of the biorefinery, in order to generate an integral use of the biomass with a minimum consumption of reagent and electricity [4]-[7]. These energy integrations in biorefineries generally contribute to the reduction of the environmental impact generated by the plant, in addition is possible to increase the profit margin [8], [9].

${ }^{*}$ Corresponding author. Tel.: +57 68879400 Ext 55354

E-mail: ccardonaal@unal.edu.co

(C) 2018 International Association for Sharing Knowledge and Sustainability

DOI: $10.5383 /$ ijtee.16.02.005
In the same sense, another aspect to take account and that is transcendental in a biorefinery, especially in the cost of production, is the scale of production [10]. A biorefinery in which were obtained biofuels such as biodiesel, ethanol, butanol among others, necessarily must be designed at a high level, since these products are produced in high volumes, due the low cost of this product. On the other hand, if the aim is to obtain products such as drugs, the scale of the biorefinery can below, due to the high cost of these products. An example in which the low scale is the obtaining of antioxidants, these products presents a high value in the market. It is important to mention that each biorefinery has its own characteristics and that all design parameters must be carefully selected for each specific case. Also, another design parameter that must be carefully analyzed in the conceptual design of the biorefinery is the selection of the raw material, since the cost of this can affect up to $60 \%$ of the overall cost of the plant. For this reason some authors have conducted studies in which recommend the use of agroindustrial wastes as raw materials in biotechnological processes [2], [11], [12]. 
The interest in the use of agroindustry residues to obtain different products has been increasing, given the different processes and products that can be obtained under this scheme [13]-[18]. Many of these residues can be used as raw material for biorefineries, providing tools for the maximum use of the raw material. One of the residues of great interest is the sugarcane bagasse ( $\mathrm{SCB}$ ), which is obtained from the milling of sugar cane. In this process can be obtained $280 \mathrm{~kg}$ of bagasse from 1 ton of sugar cane [19], [20]. The SCB can be used to obtain different products as the ethanol, xylitol, electricity, PHB, antioxidants and lactic acid, among others [21], [22].

In a biorefinery, the analysis of scale is determinant, because it's presented as a tool that allows the determination of the minimum flow of raw materials for the economic and environmental viability of the process [23]. The aim of this work is to analyze the effect of the amount of processed raw material (processing scale) on the energy, technical, economic and environmental costs of a biorefinery for the processing of sugar cane. The products to be obtained with this scheme are ethanol, xylitol, syngas and electricity. Therefore, three processing scales were considered ( 1 ton $/ \mathrm{h}, 10$ ton/h y 100 ton $/ \mathrm{h}$ ) which was based on the availability of this waste.

\section{Methodology}

\subsection{Process design}

The design of the biorefinery using SCB as raw material is shown in Fig. 1. This raw material is composed of $34.8 \%$ of cellulose, $28.96 \%$ hemicellulose, $22.62 \%$ lignin, $8.00 \%$ extractives, $1.45 \%$ protein and $4.17 \%$ ash [24]. First step was the pretreatment after the SCB size of the material was reduced until $1 \mathrm{~mm}$ in order to increase the area of contact. A dilute acid treatment is then carried out at $2 \% \mathrm{v} / \mathrm{v}$, where the kinetics used is reported by Aguilar et al. (2002) [25]. The product of this process was a xylose rich liquor which was separated from the solids by filtration. The solid fraction was subjected to enzymatic hydrolysis in order to obtain a solution rich in glucose. The kinetics used to carry out the enzyme hydrolysis was reported by Philippidis et al. (1993) [26]. The resulting solution was filtered and a solution rich in glucose and a lignin rich fraction were obtained. The glucose solution can be used to obtain ethanol through a fermentation process [27]. This process considers a previous stage of sterilization to $121^{\circ} \mathrm{C}$. The xylose obtained in one of the previous stages can be used to obtain xylitol by means of a fermentative process. For this process the microorganism used was Candida parapsilosis [28]. The purification process of the xylitol was carried out by means of precipitation in the presence of ethanol in a relation 1:1 [29]. Filtration was then carried out in order to remove precipitated xylitol.

The last product obtained in the pretreatment stage was lignin. This can be used in cogeneration processes to obtain electricity and syngas. The lignin is brought to a gasification process to generate syngas. The syngas is mainly composed of $\mathrm{H}_{2}, \mathrm{CO}$, $\mathrm{CH}_{4}$ y $\mathrm{CO}_{2}$ [30]. Given the high pressure to which this gas leaves the gasifier, it can be passed through a turbine to generate electricity.

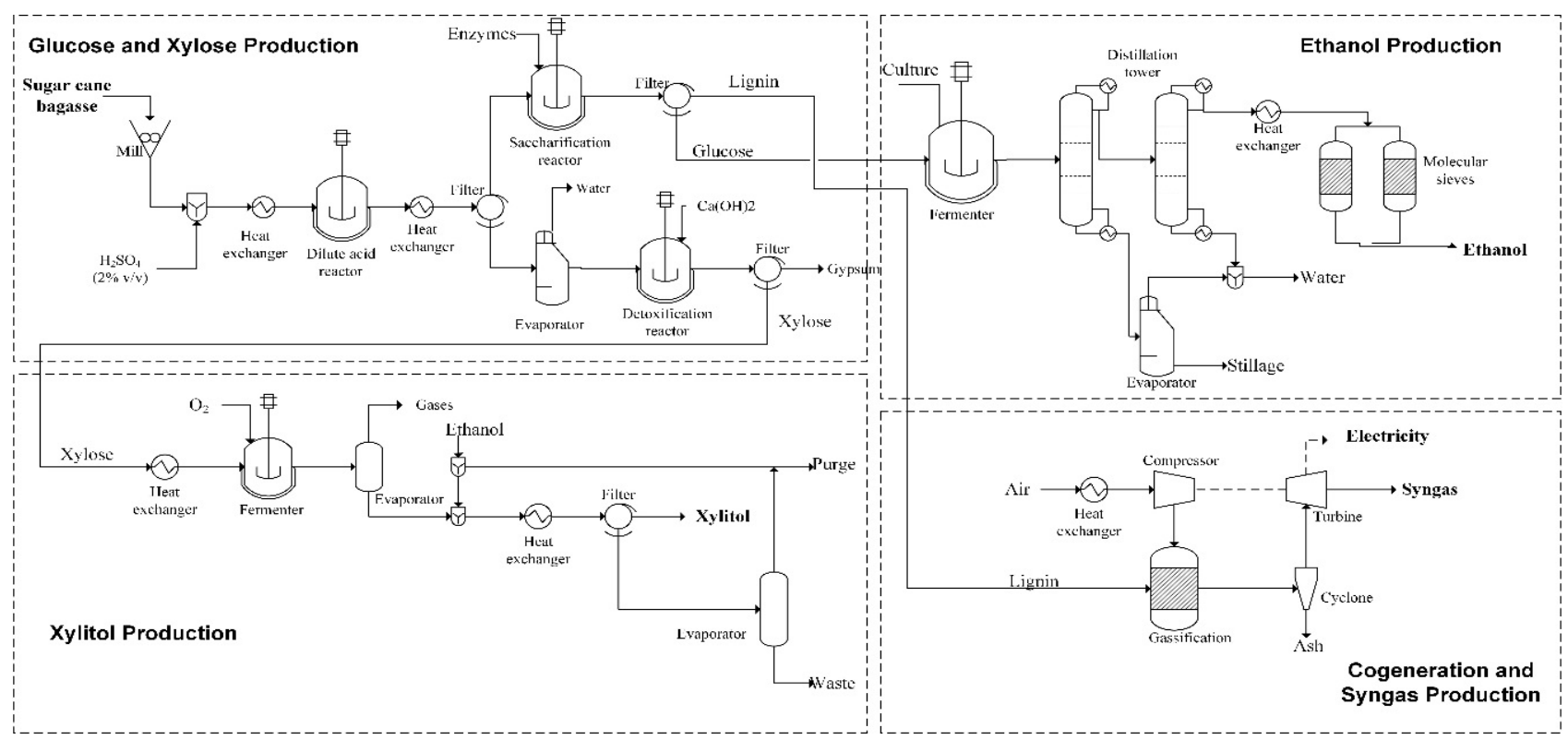

\subsection{Simulation process}

Fig. 1. Flow diagram of biorefinery.

The design of the process was carried out in the software Aspen Plus. The input data to the simulator were those reported in the literature. In the software was carried out the modeling of the stages of pretreatment and fermentation of the biorefinery. The design of the distillation towers used was done with the approximate method DSTWU incorporated in Aspen Plus. It uses the equations and correlations of Winn-UnderwoodGilliland, which provides an initial estimate of the minimum number of theoretical steps, the minimum reflux ratio, the location of the feeding stage, and the distribution of the components. The rigorous calculation of the operating conditions in the distillation columns was developed with the model RadFrac, that is based on the equilibrium method with an inside-out algorithm for calculation of equations MESH (mass balance equation, phase equilibrium equation, summation of compositions and the energy balance equation) [31]. From these procedures it is possible to obtain the mass and energy balance of the process. These are used for the energy, technical, economic and environmental analysis of the process. 


\subsubsection{Energy analysis}

In the energy analysis of the process the energy required by the heat exchangers and the reboilers is studied. It also considers the electrical needs of pumps, compressors, grinders and other equipments. The biorefinery was divided into four stages in order to carry out a comparison. The four stages are: pretreatment, ethanol production, xylitol production and cogeneration

\subsubsection{Economic analysis}

The economic analysis was done through the software Aspen Process Economic Analyzer (ASPEN TECHNOLOGY INC). The parameters used were the economic data for Colombia 25\% and $17 \%$ of Tax rate and Annual Interest rate, respectively. In depreciation, the straight-line method was used with a 12 year analysis period. In Table 1, it is presented the costs of raw materials, products, utilities and operation supplied to the software.

Table 1. Costs of raw material and parameters for the economic analysis

\begin{tabular}{|c|c|c|c|}
\hline Item & Unit & Value & Reference \\
\hline \multicolumn{4}{|c|}{ Investment Parameters } \\
\hline Tax rate & $\%$ & 25 & \multirow[b]{2}{*}[32]{} \\
\hline $\begin{array}{l}\text { Interest } \\
\text { rate }\end{array}$ & $\%$ & 17 & \\
\hline \multicolumn{4}{|c|}{ Raw materials } \\
\hline $\begin{array}{l}\text { Sugar cane } \\
\text { bagasse }\end{array}$ & $\mathrm{USD} / \mathrm{kg}$ & 0.01 & {$[33]$} \\
\hline $\begin{array}{l}\text { Sulfuric } \\
\text { acid }\end{array}$ & $\mathrm{USD} / \mathrm{kg}$ & 0.1 & \multirow{2}{*}[32]{} \\
\hline $\begin{array}{l}\text { Calcium } \\
\text { hydroxide }\end{array}$ & $\mathrm{USD} / \mathrm{kg}$ & 0.05 & \\
\hline \multicolumn{4}{|c|}{ Utilities } \\
\hline LP steam & USD/tonne & 1.57 & \multirow{3}{*}{ [34] } \\
\hline MP steam & USD/tonne & 8.18 & \\
\hline HP steam & USD/tonne & 9.86 & \\
\hline $\begin{array}{l}\text { Potable } \\
\text { water }\end{array}$ & $\mathrm{USD} / \mathrm{m}^{3}$ & 1.25 & \multirow{3}{*}{ [32] } \\
\hline Fuel & USD/MMBTU & 7.21 & \\
\hline Electricity & USD/kWh & 0.10 & \\
\hline \multicolumn{4}{|c|}{ Operation } \\
\hline Operator & $\mathrm{USD} / \mathrm{h}$ & 2.14 & \multirow{2}{*}[32]{} \\
\hline Supervisor & $\mathrm{USD} / \mathrm{h}$ & 4.29 & \\
\hline
\end{tabular}

\subsection{Environmental analysis}

The environmental analysis was performed by using the Waste Reduction Algorithm (WAR GUI) software, developed by the Environmental Protection Agency (EPA, USA). As results are obtained the effect that the raw material and energy contribute on the environment, through obtaining Potential Environmental Impact (PEI) of each of the scenarios kilogram of product [35]. The items evaluated were: Human Toxicity Potential by Ingestion (HTPI), Human Toxicity Potential by Exposure (HTPE), Terrestrial Toxicity Potential (TTP), Aquatic Toxicity Potential (ATP), Global Warming Potential (GWP), Ozone Depletion Potential (ODP), Smog Formation Potential (PCOP), and Acidification Potential (AP) [36].

\section{Results and analysis}

\subsection{Process simulation}

Under the conditions analyzed in the biorefinery design for the mentioned processing scales, the Table 2 shows the yields obtained both in obtaining sugar and other products. Compared with the literature it can be observed that a similar performance was obtained for glucose $(0.34 \mathrm{~g} / \mathrm{g}$ reported in the literature [37]). In the case of xylose, a lower yield was reported than others found in the literature $(0.29 \mathrm{~g} / \mathrm{g}$ [37]). These differences can occur at the moment of modeling a process, since the simulation of the processes is an approach to the reality at industrial scale.

On the other hand yields of $0.135,0.155$ and $0.828 \mathrm{~g}$ product $/ \mathrm{g}$ raw material were obtained for the production of ethanol, xylitol and syngas, respectively. In the case of ethanol fermentation a $\mathrm{CO}_{2}$ generation of 0.27 grams per gram of raw material was obtained and a generation of stillage of 4.45 grams per gram of raw material. This last value is due to the high water content that this residue presents due to the addition of the same to achieve a concentration of glucose suitable for the fermentation. In the production of xylitol a stillage yield of 9.99 grams per gram of raw material is obtained. Taking into account these two fermentative processes a total generation of stillage of 14.44 grams per gram of raw material is obtained. This residue presents a great potential for its use in the production of biogas, fertilizers, production of organic acids, among others [38], [39].

Table 2. Yields obtained in the design of biorefinery

\begin{tabular}{lcc}
\hline Product & \multicolumn{2}{c}{ Yield } \\
\hline Glucose & $Y_{\text {glucose } / \text { biomass }}$ & 0.335 \\
Xylose & $Y_{\text {xylose } / \text { biomass }}$ & 0.261 \\
Liginin & $Y_{\text {lignin/biomass }}$ & 0.226 \\
Ethanol & $Y_{\text {ethanol/biomass }}$ & 0.135 \\
Xylitol & $Y_{\text {xylitol/biomass }}$ & 0.155 \\
Syngas & $Y_{\text {syngas/biomass }}$ & 0.828
\end{tabular}

In the case of electricity generation, a yield of $0.130 \mathrm{~kW} / \mathrm{kg}$ of raw material was presented. This shows the technical feasibility of the SCB for the generation of electricity from the lignin contained in this material.

\subsection{Energy analysis}

A trend that has gained importance in the application and design of processes is the energy efficiency. The purpose is to identify the zones of the process that present greater energy consumption and the causes. The Fig. 2 shows the percentage distribution of the energy consumption for a biorefinery based on the SCB. Where it can be observed that with $38.72 \%$ ethanol production is the process that presents higher energy requirements. It is caused mainly by the high energy required to achieve purification of the ethanol obtained in the fermentation. In this process this energy is necessary for the implementation of a separation train which consumes a high amount of energy for its operation. While processes such as xylitol production have a lower energy consumption. In this case the processing step which requires a greater amount of energy is the recovery of the ethanol used in the precipitation of the xylitol produced. Meanwhile cogeneration initially requires a lot of energy to 
achieve the high temperatures and pressures that are required for this process. In the case of pretreatment the higher energy consumption is evidenced in the high temperature required for the acid hydrolysis and the operation of the mill. Thus, for the processing of $1 \mathrm{ton} / \mathrm{h}$ of SCB, it is required $107,135.16 \mathrm{GJ} / \mathrm{h}$. On the other hand for the processing of 10 and $100 \mathrm{ton} / \mathrm{h}$ it is required $1,071,351.62$ and $10,713,516.20 \mathrm{GJ} / \mathrm{h}$, respectively. This shows an increase in the energy consumption with the increase of the scale of processing due to the increase in the size of the equipments and therefore to the energy requirements.

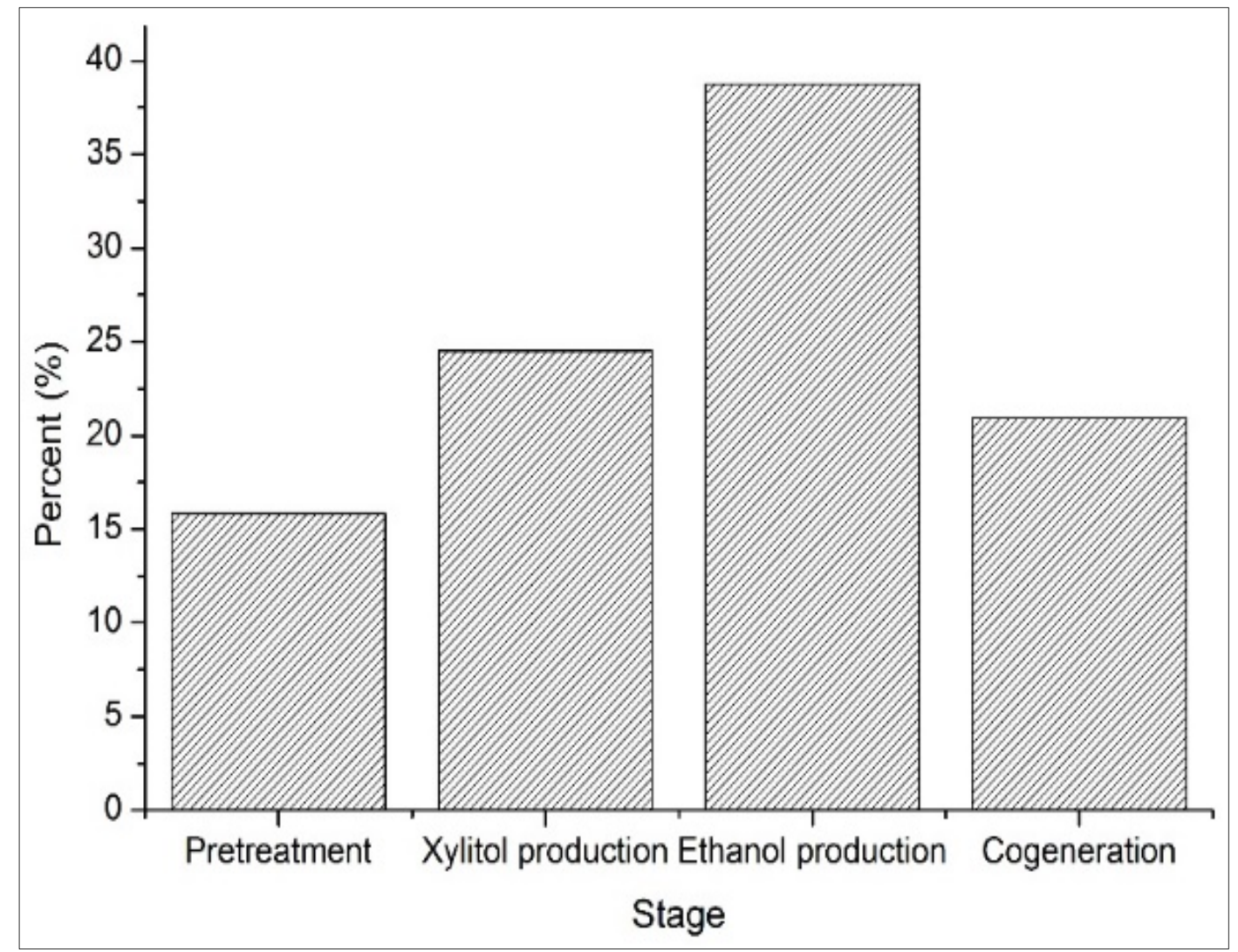

Fig. 2. Percentage distribution of energy consumption of a biorefinery based on SCB

\subsection{Economic analysis}

In Table 3, the economic analysis results are presented at 1,10 and 100 tonne/h. For each of these scales the total cost of production was calculated, obtaining the highest percentages in the cost of raw materials with $34-43 \%$ of the total production cost of ethanol, xylitol and cogeneration of energy. On the other hand, the gain obtained for each of these scenarios increased by employing a higher flow of the process (100 tonne/h), due to the high production of products and the sale price; In particular xylitol which has a market price of 164 USD / $\mathrm{kg}$ [40].

\subsection{Environmental analysis}

An essential part of the sustainability of any type of biological process and especially of a biorefinery, is that it generates low environmental impact, and also that the production of toxic products will be minimal. In This sense, as a result it was obtained that the most representative environmental impact factor for the overall environmental impact of the plant was the acidification potential (AP). This high acidification potential is due to the fact that the streams from the hydrolysis processes contain a high concentration of sulfuric acid. It can also be seen from Fig. 3.c, that the acidification potential of the medium is increased with increasing scale, since the amounts of acid used in pretreatment are higher. In the same sense, it can be inferred from Fig. 3.a that the high value of aquatic toxicity potential is related to the high acidity of the effluents as mentioned above, and possible toxic products such as HMF and furfural obtained in the pretreatment stages. It is also important to emphasize that some traces of methanol and ethanol obtained from the separation and purification stages may affect aquatic ecosystems. Also, it is evident in Fig. 3.a that this process presents a high global warming potential value, due to the carbon dioxide generated in the fermentation process and that possibly can be released into the environment. Finally, it can be concluded that the other impact factors evaluated (HTPI, HTPE, TTP, PCOP) are not representative independent of the scale, since the biorefinery was not generate potentially dangerous products for human health, either by ingestion or by exposure. 


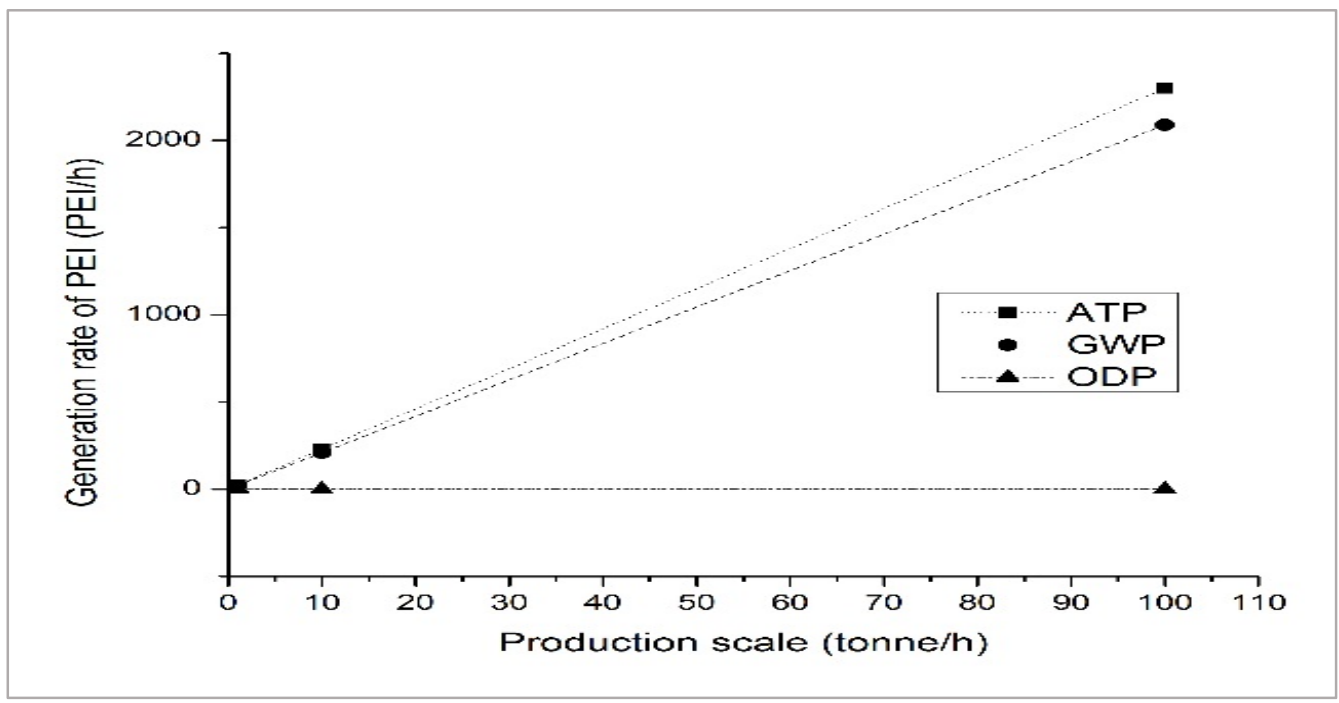

(a)

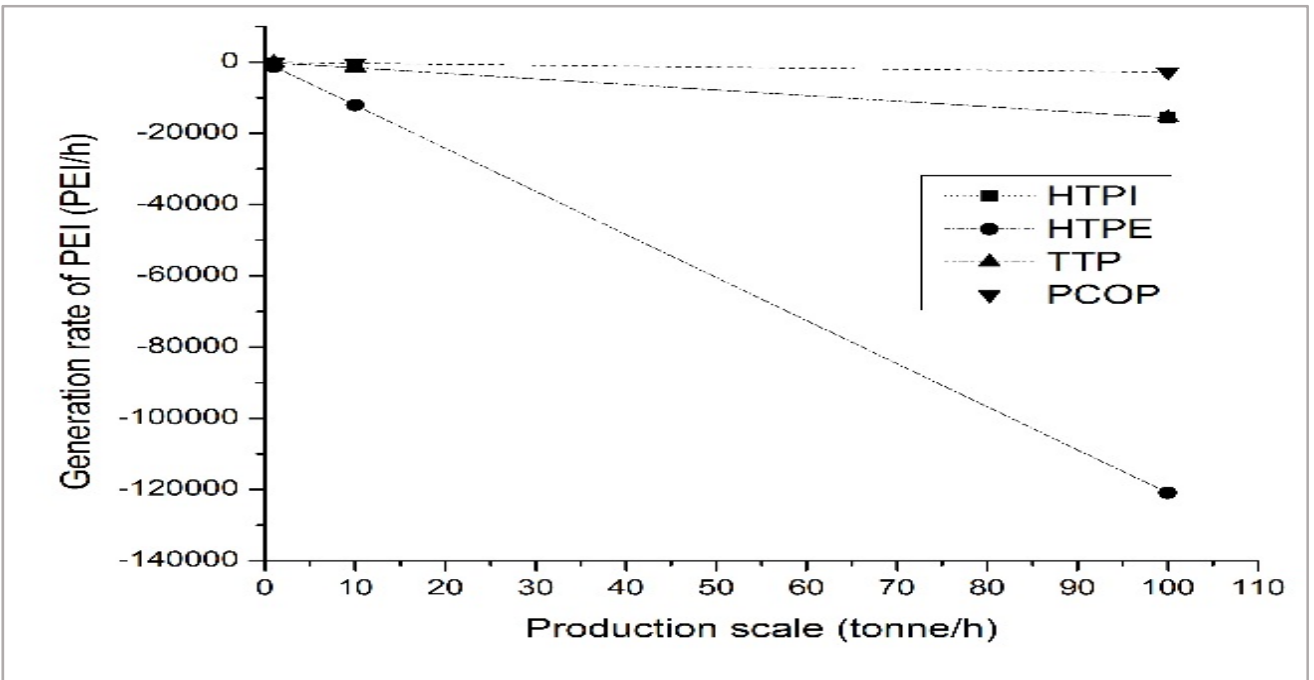

(b)

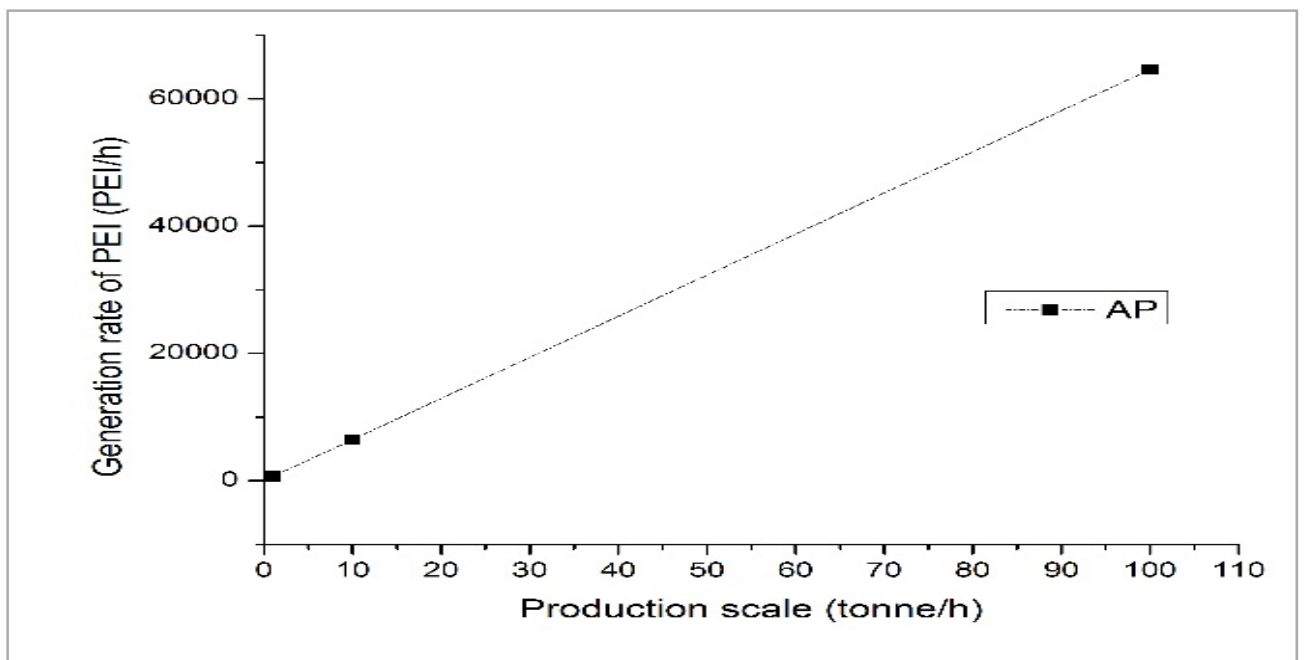

(c)

Fig. 3. Potential of Environmental Impact: a. Aquatic Toxicity Potential (ATP), Global Warming Potential (GWP) and Ozone Depletion Potential (ODP), b. Human Toxicity Potential by Ingestion (HTPI), Human Toxicity Potential by Exposure (HTPE), Terrestrial Toxicity Potential (TTP) and Smog Formation Potential (PCOP), c. Acidification Potential (AP). 
Restrepo et al. / Int. J. of Thermal \& Environmental Engineering, 16 (2018) 97-104

Table 3. Economic analysis of the production of ethanol, xylitol and energy cogeneration from SCB.

\begin{tabular}{lcccccc}
\hline \multirow{2}{*}{ Item } & \multicolumn{2}{c}{$\mathbf{1}$ tonne/h } & \multicolumn{2}{c}{$\mathbf{1 0}$ tonne/h } & \multicolumn{1}{c}{$\mathbf{1 0 0}$ tonne/h } \\
\cline { 2 - 6 } & US\$/kg & Share (\%) & US\$/kg & Share (\%) & US\$/kg & Share (\%) \\
\hline Raw materials & 0.977 & 34.545 & 0.824 & 37.804 & 0.276 & 42.814 \\
Utilities & 1.216 & 42.981 & 1.015 & 46.559 & 0.283 & 43.936 \\
Operating labor & 0.037 & 1.297 & 0.003 & 0.142 & 0.001 & 0.142 \\
Plant overhead & 0.041 & 1.439 & 0.010 & 0.442 & 0.002 & 0.379 \\
Operating charges & 0.009 & 0.324 & 0.002 & 0.088 & 0.001 & 0.155 \\
Maintenance & 0.045 & 1.582 & 0.016 & 0.741 & 0.005 & 0.726 \\
General and administrative cost & 0.174 & 6.169 & 0.138 & 6.336 & 0.042 & 6.463 \\
Capital depreciation & 0.330 & 11.663 & 0.171 & 7.848 & 0.035 & 5.488 \\
\hline Production cost (Total ) & $\mathbf{2 . 8 2 8}$ & $\mathbf{1 0 0}$ & $\mathbf{2 . 1 7 9}$ & $\mathbf{1 0 0}$ & $\mathbf{0 . 6 4 4}$ & $\mathbf{1 0 0}$ \\
\hline
\end{tabular}

\section{Conclusions}

Analysis of the scale is presented as a powerful tool for the determination of technical, energetic, economic and environmental viability of a biorefinery. From the different analysis of these aspects, it can be evidenced the technical and economic benefits that present processes such as biorefineries based on the SCB when the scale increases. While energy and environmental characteristics, tend to have greater impacts with increasing scale. This is mainly due to the increase in both energy and raw material requirements for the operation of biorefineries at high scales.

\section{Acknowledgments}

The authors express their gratitude of the Universidad Nacional de Colombia, sede Manizales.

\section{References}

[1] J. Moncada, L. G. Matallana, and C. A. Cardona, "Selection of process pathways for biorefinery design using optimization tools: A colombian case for conversion of sugarcane bagasse to ethanol, poly-3hydroxybutyrate (PHB), and energy," Ind. Eng. Chem. Res., vol. 52, no. 11, pp. 4132-4145, Mar. 2013.

[2] F. Cherubini, "The biorefinery concept: Using biomass instead of oil for producing energy and chemicals," Energy Convers. Manag., vol. 51, no. 7, pp. 14121421, Jul. 2010.

[3] H. Toivanen and M. Novotny, "The emergence of patent races in lignocellulosic biofuels , 2002 - 2015," Renew. Sustain. Energy Rev., vol. 77, no. April, pp. 318-326, 2017.
[4] F. I. Gomez-Castro, C. Gutiérrez-Antonio, A. G. Romero-Izquierdo, and J. G. Segovia-Hernandez, "Mass and energy integration for the supercritical process for biodiesel production and a bioethanol dehydration train," Comput. Aided Chem. Eng., vol. 38, pp. 487-492, 2016.

[5] J. Moncada, C. A. Cardona, and L. E. Rincón, "Design and analysis of a second and third generation biorefinery: The case of castorbean and microalgae," Bioresour. Technol., vol. 198, pp. 836-843, Dec. 2015.

[6] M. Gassner and F. Maréchal, "Combined mass and energy integration in process design at the example of membrane-based gas separation systems," Comput. Chem. Eng., vol. 34, no. 12, pp. 2033-2042, Dec. 2010.

[7] M. Vázquez-Ojeda, J. G. Segovia-Hernández, and J. M. Ponce-Ortega, "Incorporation of Mass and Energy Integration in the Optimal Bioethanol Separation Process," Chem. Eng. Technol., vol. 36, no. 11, pp. 1865-1873, Nov. 2013.

[8] R. Nitzsche, M. Budzinski, and A. Gröngröft, "Technoeconomic assessment of a wood-based biorefinery concept for the production of polymer-grade ethylene, organosolv lignin and fuel," Bioresour. Technol., vol. 200, pp. 928-939, Jan. 2016.

[9] J. A. Quintero et al., "Social and techno-economical analysis of biodiesel production in Peru," Energy Policy, vol. 43, pp. 427-435, Apr. 2012.

[10] C. D. Botero, D. L. Restrepo, and C. A. Cardona, "A comprehensive review on the implementation of the biorefinery concept in biodiesel production plants," Biofuel Res. J., vol. 4, no. 3, pp. 691-703, 2017.

[11] B. Kamm and M. Kamm, "Principles of biorefineries Received:," Appl Biochem Biotechnol, vol. 64, pp. 
137-145, 2004.

[12] I. Cerón-Salazar and C. Cardona-Alzate, "Integral evaluation process for obtaining pectin and essential oil from orange peel," Ing. y Cienc., vol. 7, no. 13, pp. 1794-9165, 2011.

[13] M. Nitschke, C. Ferraz, and G. M. Pastore, "Selection of microorganisms for biosurfactant production using agroindustrial wastes," Brazilian J. Microbiol., vol. 35, no. 1-2, pp. 81-85, Jun. 2004.

[14] R. Singh, V. Kapoor, and V. Kumar, "Utilization of Agro-industrial Wastes for the Simultaneous Production of Amylase and Xylanase by Thermophilic Actinomycetes.," Braz. J. Microbiol., vol. 43, no. 4, pp. 1545-52, Oct. 2012.

[15] S. I. Mussatto, L. F. Ballesteros, S. Martins, and J. A. Teixeira, "Use of Agro-Industrial Wastes in Solid-State Fermentation Processes," in Industrial Waste, Prof. Kuan-Yeow Show (Ed.) InTech, 2012.

[16] M. O. S. Dias, A. V. Ensinas, S. A. Nebra, R. Maciel Filho, C. E. V. Rossell, and M. R. W. Maciel, "Production of bioethanol and other bio-based materials from sugarcane bagasse: Integration to conventional bioethanol production process," Chem. Eng. Res. Des., vol. 87, no. 9, pp. 1206-1216, 2009.

[17] K. Hofsetz and M. A. Silva, "Brazilian sugarcane bagasse: Energy and non-energy consumption," Biomass and Bioenergy, vol. 46, pp. 564-573, 2012.

[18] A. K. Chandel, S. S. da Silva, W. Carvalho, and O. V. Singh, "Sugarcane bagasse and leaves: foreseeable biomass of biofuel and bio-products," J. Chem. Technol. Biotechnol., vol. 87, no. 1, pp. 11-20, Jan. 2012.

[19] C. A. A. Cardona, J. A. A. Quintero, and I. C. C. Paz, "Production of bioethanol from sugarcane bagasse: Status and perspectives," Bioresour. Technol., vol. 101, no. 13, pp. 4754-4766, Jul. 2010.

[20] A. Pandey, C. R. Soccol, P. Nigam, and V. T. Soccol, "Biotechnological potential of agro-industrial residues. I: sugarcane bagasse," Bioresour. Technol., vol. 74, no. 1, pp. 69-80, 2000.

[21] J. Moncada, M. M. El-Halwagi, and C. A. Cardona, "Techno-economic analysis for a sugarcane biorefinery: Colombian case," Bioresour. Technol., vol. 135, pp. 533-543, May 2013.

[22] S. I. Mussatto, J. Moncada, I. C. Roberto, and C. A. Cardona, "Techno-economic analysis for brewer's spent grains use on a biorefinery concept: The Brazilian case," Bioresour. Technol., vol. 148, pp. 302-310, Nov. 2013.

[23] E. De Jong and G. Jungmeier, "Bioreenery Concepts in Comparison to Petrochemical Reeneries," in Industrial Biorefineries and White Biotechnology, Elservier B. V., 2015, pp. 3-33.

[24] J. A. Quintero, J. Moncada, and C. A. Cardona, "Techno-economic analysis of bioethanol production from lignocellulosic residues in Colombia: A process simulation approach,” Bioresour. Technol., vol. 139, pp. 300-307, Jul. 2013.
[25] R. Aguilar, J. A. Ramírez, G. Garrote, and M. Vázquez, "Kinetic study of the acid hydrolysis of sugar cane bagasse,” J. Food Eng., vol. 55, no. 4, pp. 309-318, 2002.

[26] G. P. Philippidis, T. K. Smith, and C. E. Wyman, "Study of the Enzymatic Hydrolysis of Cellulose for Production of Fuel Ethanol by the Simultaneous Saccharification and Fermentation Process," vol. 41, pp. 846-853, 1993.

[27] J. A. Quintero and C. A. Cardona, "Ethanol Dehydration by Adsorption with Starchy and Cellulosic Materials," Ind. Eng. Chem. Res., vol. 48, no. 14, pp. 6783-6788, Jul. 2009.

[28] J. S. Aranda-Barradas, M. L. Delia, and J. P. Riba, "Kinetic study and modelling of the xylitol production using Candida parapsilosis in oxygen-limited culture conditions," Bioprocess Eng., vol. 22, no. 3, pp. 219225, Mar. 2000.

[29] S. I. Mussatto, J. C. Santos, W. C. R. Filho, and S. S. Silva, "Purification of xylitol from fermented hemicellulosic hydrolyzate using liquid - liquid extraction and precipitation techniques," Appl. Energy, vol. 123, pp. 108-120, 2014.

[30] K. Manatura, J.-H. Lu, K.-T. Wu, and H.-T. Hsu, "Exergy analysis on torrefied rice husk pellet in fluidized bed gasification," Appl. Therm. Eng., vol. 111, pp. 1016-1024, Jan. 2017.

[31] J. Quintero and Et Al, "Evaluación de la deshidratación de alcohol carburante mediante simulación de procesos," Fac. Ciencias Agropecu., vol. 5, pp. 73-83, 2007.

[32] J. A. Dávila, V. Hernández, E. Castro, and C. A. Cardona, "Economic and environmental assessment of syrup production. Colombian case," Bioresour. Technol., vol. 161, pp. 84-90, 2014.

[33] S. H. Duque, C. A. Cardona, and J. Moncada, "TechnoEconomic and Environmental Analysis of Ethanol Production from 10 Agroindustrial Residues in Colombia," Energy Fuels, vol. 29, no. 2, pp. 775-783, 2015.

[34] J. Moncada, V. Hernández, Y. Chacón, R. Betancourt, and C. A. Cardona, "Citrus Based Biorefineries," in Citrus Fruits. Production, Consumption and Health Benefits, D. Simmons, Ed. Nova Publishers, 2015, pp. $1-26$.

[35] D. Young, R. Scharp, and H. Cabezas, "The waste reduction (WAR) algorithm: environmental impacts, energy consumption, and engineering economics," Waste Manag., vol. 20, no. 8, pp. 605-615, Dec. 2000.

[36] D. M. Young and H. Cabezas, "Designing sustainable processes with simulation: The waste reduction (WAR) algorithm," Comput. Chem. Eng., vol. 23, no. 10, pp. 1477-1491, 1999.

[37] R. Velmurugan and K. Muthukumar, "Utilization of sugarcane bagasse for bioethanol production: Sono assisted acid hydrolysis approach," Bioresour. Technol., vol. 102, pp. 7119-7123, 2011. 
[38] A. C. Wilkie, K. J. Riedesel, J. M. Owens, and A. C. Wilkie, "Stillage characterization and anaerobic treatment of ethanol stillage from conventional and cellulosic feedstocks," Biomass and Bioenergy, vol. 19, pp. 63-102, 2000.

[39] M. A. Mutton, R. Rossetto, and M. J. Rossini Mutton, "Agricultural use of stillage," in Sugarcane bioethanol
- R\&D for Productivity and Sustainability, Edgard Blücher, Ed. São Paulo, 2014, pp. 423-440.

[40] "Sigma-Aldrich." [Online].

Available: https://www.sigmaaldrich.com/us-export.html. [Accessed: 13-Jul-2017]. 